\title{
A User-Friendly Theoretical Mathematical Model for the Prediction of Food Safety in a Food Production Chain
}

Angeliki Birmpa ${ }^{1}$, Apostolos Vantarakis ${ }^{1 *}$, Antigoni Anninou ${ }^{2}$, Maria Bellou ${ }^{1}$, Petros Kokkinos ${ }^{1}$ and Peter Groumpos ${ }^{2}$

${ }^{1}$ Environmental Microbiology Unit, Department of Public Health, Medical School, University of Patras, GR26500, Rio, Patras, Greece

${ }^{2}$ Laboratory for Automation and Robotics, Department of Electrical and Computer Engineering, University of Patras, GR26500, Rio, Patras, Greece

\begin{abstract}
Minimally processed vegetables have recently undergone a significant increase in consumer demand because of their healthy image and convenience of use. Some of these products can be contaminated by microbial pathogens, as some have been implicated in an increasing number of outbreaks of foodborne illnesses. The aim of the present paper was the development of a Decision Support System (DSS) using the theory of Fuzzy Cognitive Maps (FCMs), in order to diagnose the importance of critical control points (concepts) for the food safety and hygiene during the production of salad vegetables (lettuce). The methodology described, extracts the knowledge from experts with different scientific background and exploits their experience on the process of lettuce production. The results of this study show that software tools like Food Science Support Systems using theories of FCMs can be explored and problems that can arise during the food production chain can be prevented if the importance of some critical control points during the food production is previously indicated.
\end{abstract}

Keywords: Decision support system experts; Food safety; Fuzzy cognitive maps; Lettuce production chain; Software tool

\section{Introduction}

Today's society is characterized by an increasing health consciousness and growing interest in the role of food for maintaining and improving human well-being and consumer health $[1,2]$. Vegetables and fruits are fully recognized for their benefits towards healthy living [3], thanks to their protective function against cancer and other chronic degenerative diseases [4,5]. At present Europe is the largest importer and exporter of food products in the world, the safety of which is managed by the EU food policy, developed to support the consumer's confidence in food safety [6].

However, food-borne outbreaks happen quite often. The most common outbreaks caused by food-borne pathogens of fresh produce are mainly Cryptosporidium parvum, Listeria monocytogenes, Escherichia coli O157:H7, Salmonella spp., Clostridium botulinum, Shigella spp., Cyclospora spp., and Noroviruses [7,8]. These pathogens can cause infection and illness by the fecal-oral route of food contamination [9,10]. In 2006, E. coli O157:H7 infected bagged spinach causing three deaths and 102 hospitalizations [11]. In 2008, Alaska experienced a Campylobacter outbreak from peas contaminated by crane droppings, causing 99 illnesses [12]. In 2010 and 2011, Salmonella infected alfalfa sprouts, causing 125 illnesses (CDC, 2011). Escherichia coli outbreaks with lettuce occurred in 2010 and 2011 (CDC, 2010; CDC, 2011). Surprisingly, most pathogens do not originate from the food they contaminate but are transported to produce through other means, including household cross contamination [13]. Quality assurance and control measures must be in place in different stages of the fresh produce chain (from farm to fork).

The lettuce/leafy greens industry recognizes that once lettuce/ leafy greens are contaminated, removing or inactivate pathogens is difficult. Therefore, prevention of microbial contamination at all steps from production to distribution is strongly favored over treatments to eliminate contamination after it has occurred. Thus, lettuce/leafy greens food safety programs should pay special attention to controlling, reducing and eliminating potential fecal contamination. Lettuce/leafy greens may be harvested mechanically or by hand and are almost always consumed uncooked or raw. In addition, lettuces are characterized by high water activity levels, which make them more vulnerable to crosscontamination. In a processing operation, the basic principles of Good Manufacture Practices (GMPs), HACCP, sanitation and documented operating procedures are commonly employed to ensure production of the safest products possible. The complexity of food systems and the large number of "critical points" in food production chain impose the necessity of the development of mathematical models for the prediction of food safety as well as the prevention of contamination. New practices, predictive models, methods and valuable tools have been emerging as complements to decisions taken in Food Science problems.

Several types of models are used ranging from qualitative (e.g., tree structure) to quantitative (e.g., microbial growth models) [14]. Prototype dynamic models which describe the growth and inactivation of a microbial population as a function of time and temperature have already been presented by Baranyi et al. and Van Impe et al. $[15,16]$. Predictive models (PM) can be produced within a few days, which can be augmented or modified ensuring that PM becomes a timely tool for product development [17]. A computerized food design support system already exists for the simulation of developing and optimizing food products [18]. On the other hand, it is difficult to develop a classical automated approach due in part to: (1) many dimensions that must be taken into account in parallel, and (2) non-linearity and coupling between the variables involved in the system.

Meanwhile, Decision Support Systems (DSS) in the field of Food Science require flexibility, autonomy, intelligence, reliability but above all should be trusted by people related to Food Science. To fulfil all these

*Corresonding author: Apostolos Vantarakis, Environmental Microbiology Unit, Department of Public Health, Medical School, University of Patras, GR26500 Patras, Greece, E-mail: avanta@upatras.gr

Received December 23, 2014; Accepted January 30, 2014; Published February 06, 2015

Citation: Birmpa A, Vantarakis A, Anninou A, Bellou M, Kokkinos P, et al. (2015) A User-Friendly Theoretical Mathematical Model for the Prediction of Food Safety in a Food Production Chain. J Food Process Technol 6: 421. doi:10.4172/21577110.1000421

Copyright: ( 2015 Birmpa A, et al. This is an open-access article distributed under the terms of the Creative Commons Attribution License, which permits unrestricted use, distribution, and reproduction in any medium, provided the original author and source are credited. 
diverse and difficult requirements, food scientists in close collaboration with scientists and engineers investigate new models and techniques that will integrate and combine known advanced theories and new techniques that will be the core of these sophisticated systems [19]. A Decision Support System (DSS) is defined as any interactive computer - based support system for making decisions in any complex system, when individuals or a team of people are trying to solve unstructured problems on an uncertain environment. DSS are especially valuable in situations in which the amount of "scientific data" is prohibitive for the "human decision maker" to precede in solving difficult problems [20]. Advanced DSS can aid human cognitive deficiencies by integrating various methodologies and tools utilizing a number of different information sources in order to reach "acceptable decisions". The benefits in using DSS are that they increase efficiency, productivity, competitiveness, and offer cost effectiveness and high reliability. This could give to a food science business a comparative advantage over other competitors [21].

Fuzzy Cognitive Maps are a combination of methods of fuzzy logic (FL) and neural networks. Fuzzy logic develops multi-valued, non-numeric linguistic variables for modelling human reasoning in an imprecise environment. FL has been applied in solving problems in crop management, soil and water, food quality and safety, animal health and behaviour, agricultural vehicle control, precision agriculture, greenhouse control, agricultural machinery, food processing, air quality and pollution, agricultural facilities, agricultural robotics, chemical application, and others such as natural resources management and agricultural product design [22]. Artificial Neural Networks (ANNs) provide a way to emulate biological neurons to solve complex problems in the same manner as the human brain. ANNs have the largest body of applications in agricultural and biological engineering when compared with other soft computing techniques. ANNs have been applied in solving problems in food quality and safety, crop, soil and water, precision agriculture, animal management, post-harvest, food processing, greenhouse control, agricultural vehicle control and agricultural machinery.

The purpose of this paper was to focus on the construction and the use of FCM in modelling a fit-for-purpose Decision Support System which diagnoses the possibility of the cross-contamination of lettuce from production to the point of sale in a vertical production company of vegetables.

\section{Material and Methods}

\section{Selection of critical points}

Nine critical points were selected from three (3) experts, with different scientific background, as they play a crucial role throughout the lettuce production procedure (Figure 1). The selection of critical points was based on background information questionnaires, based on HACCP audit principles, which were completed for the premise during the European FP7 project VITAL (Integrated Monitoring and Control of Foodborne Viruses in European Food Supply Chains) aimed to gather data on virus contamination with the aim of providing a basis for subsequent quantitative viral risk assessment and recommendation of control measures. These critical points were selected among others as the most important ones to be taken seriously into consideration, in order to be able to estimate the infection risk for humans through consumption of the leafy vegetables.

Labour, Manpower: Vegetable production is a very labour intensive work which requires both dedication and skill to effectively undertake

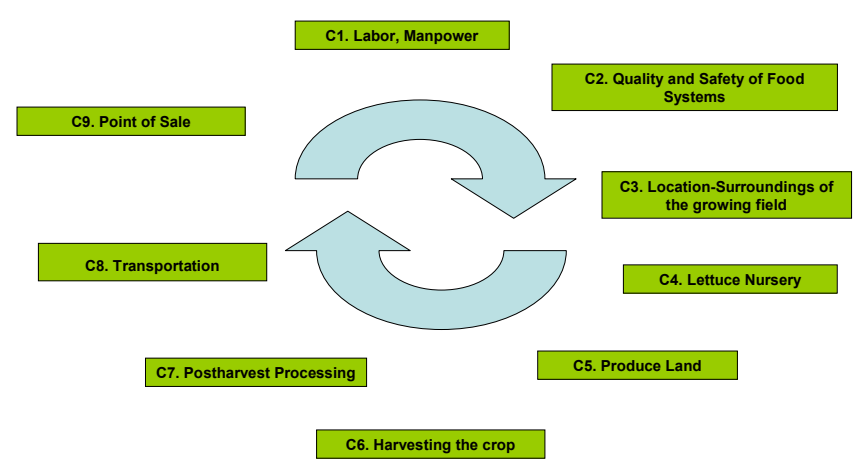

Figure 1: Flow Chart of Lettuce/Leafy Greens Production.

it. Basic training in agronomic principles or experience in the same field is very crucial. Moreover, hygiene training is of great importance. Lettuce/leafy greens may be harvested mechanically or by hand and are almost always consumed uncooked or raw. Because lettuce/leafy greens may be hand-harvested and hand-sorted for quality, there are numerous "touch points" early in the supply chain and a similar number of "touch points" later in the supply chain as the products are used in foodservice or retail operations. Each of these "touch points" represents a potential opportunity for cross-contamination. Emphasis in hand washing where there is risk of contamination (e.g. before starting work, after using the bathroom, etc.) must be given. Workers with any notifiable infectious disease must be excluded from work. Harvesting equipment (knifes) should be cleaned and/or sanitised daily. Suitable protective clothing has to be worn by food workers, except for disposable gloves.

Quality and safety of food systems: The existence of Good Agricultural Practices (Global, GAP) is a necessity in a vegetable company. Internal and external auditing must be in place. Quality systems, i.e. ISO 22000, Sanitation Standard Operating Procedures (SSOPs) must be present throughout the food supply chain. HACCP guidelines are also important so as to ensure the safe production and handling of lettuce/leafy greens products from field to fork. The Recommended International Code of Practice General Principles of Food Hygiene [23] indicates that "Prior to application of HACCP to any sector of the food chain, that sector should have in place prerequisite programs such as good hygienic practices according to the Codex General Principles of Food Hygiene, the appropriate Codes of Practice, and appropriate food safety requirements" [24].

Location-surroundings of the growing field: Caution must be given with domestic animals which in primary production must not have access or presence on the premises. Moreover, emphasis must be given to the place of storage of raw manure and to the existence or not of any industrial, and/or farming activity adjacent to the field. Fields that contain animal manure are more likely to be contaminated with enteric pathogens because of their ability to survive in soils for months or years. Faeces may naturally contain between $10^{2}$ and $10^{5} \mathrm{CFU} / \mathrm{g} E$. coli and between $10^{2}$ and $10^{7} \mathrm{CFU} / \mathrm{g}$ Salmonella spp. [25].

Lettuce nursery: The quality of lettuce nursery is of great importance. Melotto et al. [26] reported that phytopathogen infections, which occur frequently during field cultivation, could affect the interaction between human pathogens and plants [27]. Microbial and chemical testing of products can be carried out in accredited laboratories on a scheduled base and the results must be satisfactory. A labelling and traceability system as well as a recall system must be in place. 
Produce land: Lettuce grows best in fields that are level and well drained. Lettuce is highly sensitive to salinity. High salinity causes one of the most widespread types of abiotic stress worldwide, severely limiting crop productivity [28]. Thus, the choice of soil with an appropriate electrical conductivity is highly desirable. Land used for lettuce is often pre-irrigated before land preparation is completed to facilitate salt leaching. The variety and seed selection as well as the seed handling are very important. The irrigation and the cultivation procedure are key elements in the production of lettuce [29].

Harvesting the crop: The handling technique that will be followed is important during the harvesting. Because most lettuce undergoes little processing, great emphasis is placed on producing a high quality product. It is essential that the product be free of pest damage and contamination at harvest. Lettuce is open to contamination from a wide variety of sources that includes manure amended soil, irrigation water, insects and wild animals [30]. A wash step is applied in fresh-cut processing in an attempt to remove field acquired contamination or at least prevent cross-contamination between batches [31-33]. Lettuce trimming and coring-in-field (CIF) are relatively recent industry developments designed to increase processing plant production. This process significantly reduces shipping and waste disposal costs while maintaining the market quality of lettuce [34]. However, core removal requires additional human handling per head in the field and exposes the internal leaf tissues, increasing the risk of direct contamination, which is already high in field environments [35]. Cut leaf tissues, such as those resulting from coring, provide a moist, nutrient rich environment especially conducive to direct and rapid infiltration, and pathogen attachment, growth and survival $[36,37]$.

Postharvest processing: Field packaged lettuce can be packed "naked" in the carton, film-wrapped in perforated or non-perforated cellophane; or bagged in perforated plastic bags. After harvest, the lettuce is transported to a cooling shed and distribution centre where it is stored at low temperatures and it must be shipped with 48 hours. Cross contamination combined with the growth of pathogens during storage are fundamental risk factors for listeriosis $[38,39]$.

Transportation: The transport of fresh fruit and vegetables is a complicated topic. The equipment should be maintained in good condition, and the cleaning frequency must be documented and verified. The storage/carriage conditions afforded the produce should be such that excessive water loss does not occur. Optimum transit temperature is around $0^{\circ} \mathrm{C}$, container temperature $1-2^{\circ} \mathrm{C}$, and relative humidity 90 $95 \%$. Fast transportation with minimum damage during shipment is vey important in successful marketing of perishable. Although optimal storage temperature $\left(0-2^{\circ} \mathrm{C}\right)$ is very useful for prolonging the shelf-life of vegetables, the recommended temperature is not always maintained during postharvest storage and normal temperature is usually found during the transportation of lettuce from farm to retails since some of the transportation equipment are open air vehicles [40].

Point of sale: The lettuce packaging should be designed to preserve the content as fresh and safe as possible. Its second function is to make the product look attractive to customers, using colourful prints. In addition, cross contamination might be occurred during the period of transport or storage in the market, restaurant and home. Moreover, the final packing containers must be properly handled in order to prevent cross-contamination and be kept covered. The premises must be regularly cleaned according to a documented cleaning plan.

\section{Decision Making Support System in lettuce's safety using fuzzy cognitive maps}

The concepts that were selected to be tested during the lettuce production procedure were extracted from questionnaires that were filled from experts. The methodology described extracts the knowledge from experts and exploits their experience of the process. Each expert based on his/her experience knows the main factors that contribute to the decision. Experts describe the existing relationship firstly as "negative" or "positive" and secondly, as a degree of influence using a linguistic variable, such as "low", "medium", "high" etc.

More specifically, the causal interrelationships among concepts are declared using the variable influence which is interpreted as a linguistic variable taking values in the universe of discourse $\mathrm{U}=[-1,1]$. Its term set $\mathrm{T}$ (influence) is suggested to be comprised of nine variables. Using nine linguistic variables, an expert can describe the influence of one concept on another in detail and can discern it between different degrees. The nine variables used here are: $\mathrm{T}$ (influence) $=$ \{negatively very strong, negatively strong, negatively medium, negatively weak, zero, positively weak, positively medium, positively strong, positively very strong\}. The corresponding membership functions for these terms are shown in Figure 2 and they are $\mu \mathrm{nvs}, \mu \mathrm{ns}, \mu \mathrm{nm}, \mu \mathrm{nw}, \mu \mathrm{z}, \mu \mathrm{pw}, \mu \mathrm{pm}, \mu \mathrm{ps}$ and $\mu \mathrm{pvs}$.

With this method the purpose is to diagnose and predict the effect of different factors during the lettuce production chain in their contribution to a final safe fresh lettuce.

\section{Theory/calculation}

FCMs are a combination of methods of fuzzy logic and neural networks. It is a flexible computational method, which is able to consider situations in which human reasoning process includes fuzzy and uncertain descriptions. FCMs are fuzzy-graph structures for representing causal reasoning. Their fuzziness allows hazy degrees of causality between causal objects (concepts). The effect and the interrelationships between the nodes should be calculated, in order to create a FCM. Each node is a concept, a main feature of the system. Each interrelationship between the nodes represents a cause-effect relationship that exists between concepts and determines the manner that one concept influences on the value of the interconnected concepts. The Figure 2 shows the representation of FCMs. $\mathrm{W}_{\mathrm{ij}}$ are the weights among concepts and they take their values in the universe of discourse $\mathrm{U}=[-1,1]$. Each expert describes the interconnections using linguistic variables, which with a defuzzification method are transformed to a numerical weight $\mathrm{W}_{\mathrm{ij}}$, belonging to the interval $[-1,1]$.

- $\mathrm{W}_{\mathrm{ij}}>0$ positive causality, which means that when the value

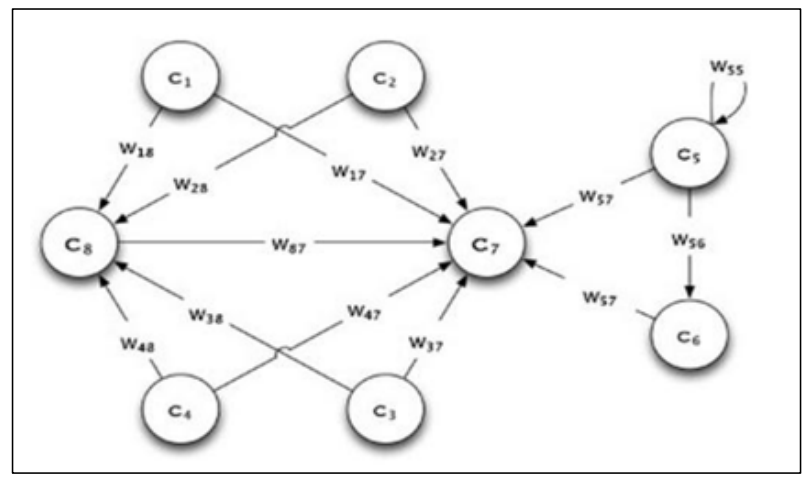

Figure 2: The FCM Model. 
of concept $\mathrm{C}_{\mathrm{i}}$ is increased the value of the concept $\mathrm{C}_{j}$ is also increased.

- $\mathrm{W}_{\mathrm{ij}}<0$ negative causality, which means that when the value of concept $C_{i}$ is increased the value of the concept $C_{j}$ is decreased.

- $\mathrm{W}_{\mathrm{ij}}=0$ no relationship between the concepts.

Generally, the value of each concept at every simulation step is calculated, computing the influence of the interconnected concepts to the specific concept, by applying the following calculation rule:

$$
A_{i}^{(k+1)}=f\left(k_{2} A_{i}^{(k)}+k_{1} \sum_{\substack{j \neq i \\ j=1}}^{N} A_{j}^{(k)} W_{j i}\right)
$$

where $A_{i}^{(k+1)}$ is the value of the concept $C_{i}$ at the iteration step $k+1$, $\mathrm{A}_{\mathrm{i}}^{(\mathrm{k})}$ is the value of the concept $\mathrm{C}_{\mathrm{j}}$ at the iteration step $\mathrm{k}, \mathrm{W}_{\mathrm{ij}}$ is the weight of interconnection from concept $\mathrm{C}_{i}$ to concept $\mathrm{C}_{\mathrm{j}}$ and $\mathrm{f}$ is the sigmoid function. " $k_{1}$ " expresses the influence of the interconnected concepts in the configuration of the new value of the concept $A_{i}$ and $k_{2}$ represents the proportion of the contribution of the previous value of the concept in the computation of the new value.

The sigmoid function $\mathrm{f}$ belongs to the family of squeezing functions, and the following function is usually used to describe it:

$$
f=\frac{1}{1+e^{-\lambda x}}
$$

This is the unipolar sigmoid function, in which $\lambda>0$ determines the steepness of the continuous function $\mathrm{f}(\mathrm{x})$.

\section{Results and Discussion}

In the present study, a computerised food decision support system is described. Soft computing is a set of computing techniques, such as Fuzzy Logic (FL), Artificial Neural Networks (ANNs), and Genetic Algorithms (GAs). These computing techniques, unlike hard computing, which refers to a huge set of conventional techniques such as stochastic and statistical methods, offer somewhat "inexact" solutions of very complex problems through modelling and analysis with a tolerance of imprecision, uncertainty, partial truth, and approximation.

In our study, FCMs were used, which are a combination of methods of fuzzy logic and neural networks. FL is a form of multivalued logic derived from fuzzy set theory to deal with reasoning that is approximate, rather than precise. In contrast to yes/no or $0 / 1$ binary logic (crisp), FL provides a set of membership values inclusively between 0 and 1 to indicate the degree of truth (fuzzy). ANNs provide a way to emulate biological neurons to solve complex problems in the same manner as the human brain.

The computation of the weights is undertaken by experts and their cooperation will decide the weights. In the specific case there are three experts who assess and evaluate the relationships between each critical control point by using linguistic variables (Tables 1-3).

Experts participated in the European FP7 project VITAL. During the project (3,5 years period) the experts filled in background information questionnaires from a vertical production enterprise located in Western Peloponnesus, which produces lettuces for the Greek market and also exports to a few EU countries, performed fact finding missions, and participated in monthly sampling campaigns. Thus, the data used to feed the presenting model were "real-world" data.

\begin{tabular}{|c|c|c|c|c|c|c|c|c|c|c|}
\hline & C1 & C2 & C3 & C4 & C5 & C6 & C7 & C8 & C9 & $\begin{array}{c}\text { C10 } \\
\text { (OUTPUT) }\end{array}$ \\
\hline C1 & - & M & - & - & - & VS & M & M & W & - VS \\
\hline C2 & VS & - & M & M & - & VS & VS & VS & M & - VS \\
\hline C3 & - & M & - & - & M & - & - & - & - & - W \\
\hline C4 & - & M & - & - & - & - & - & - & - & - \\
\hline C5 & - & - & M & - & - & - & - & - & - & W \\
\hline C6 & - & M & - & - & - & - & W & - & - & W \\
\hline C7 & - & M & - & - & - & W & - & W & - & W \\
\hline C8 & - & M & - & - & - & - & W & - & - & W \\
\hline C9 & - & - & - & - & - & - & - & - & - & $-W$ \\
\hline $\begin{array}{c}\text { C10 } \\
\text { (OUTPUT) }\end{array}$ & - & - & - & - & - & - & - & - & - & - \\
\hline
\end{tabular}

\begin{tabular}{|c|c|c|c|c|c|c|c|c|c|c|}
\hline & C1 & C2 & C3 & C4 & C5 & C6 & C7 & C8 & C9 & $\begin{array}{c}\text { C10 } \\
\text { (OUTPUT) }\end{array}$ \\
\hline C1 & - & VS & - & $-W$ & - & VS & VS & $-M$ & W & -VS \\
\hline C2 & VS & - & - & W & - & $S$ & $S$ & $M$ & $M$ & $S$ \\
\hline C3 & $-M$ & W & - & - & $-S$ & - & - & - & $-\mathrm{M}$ & $-M$ \\
\hline C4 & - & - & - & - & - & - & - & - & $-W$ & - \\
\hline C5 & $-W$ & w & -S & - & - & - & - & - & $-S$ & $-M$ \\
\hline C6 & - & - & - & - & W & - & $\mathrm{M}$ & $\mathrm{M}$ & $-S$ & $-M$ \\
\hline C7 & - & - & - & - & - & $M$ & - & W & $S$ & $-M$ \\
\hline C8 & - & - & - & - & - & $M$ & W & - & $-M$ & $-W$ \\
\hline C9 & - & - & - & - & - & - & $M$ & $-M$ & - & $-W$ \\
\hline $\begin{array}{c}\text { C10 } \\
\text { (OUTPUT) }\end{array}$ & - & - & - & - & - & - & - & - & - & - \\
\hline
\end{tabular}

Table 1: First Expert.

Table 2: Second Expert.

\begin{tabular}{|c|c|c|c|c|c|c|c|c|c|c|}
\hline & C1 & C2 & C3 & C4 & C5 & C6 & C7 & C8 & C9 & $\begin{array}{c}\text { C10 } \\
\text { (OUTPUT) }\end{array}$ \\
\hline C1 & - & S & - & - & - & VS & VS & $-M$ & W & - VS \\
\hline C2 & VS & - & W & W & - & VS & VS & S & M & S \\
\hline C3 & - W & M & - & - & $-M$ & - & - & - & - W & - M \\
\hline C4 & - & W & - & - & - & - & - & - & - W & - \\
\hline C5 & - W & W & W & - & - & - & - & - & - & W \\
\hline C6 & - & W & - & - & - & - & W & W & - M & W \\
\hline C7 & - & W & - & - & - & W & - & W & W & W \\
\hline C8 & - & W & - & - & - & W & W & - & - W & W \\
\hline C9 & - & - & - & - & - & - & W & - M & - & - W \\
\hline $\begin{array}{c}\text { C10 } \\
\text { (OUTPUT) }\end{array}$ & - & - & - & - & - & - & - & - & - & - \\
\hline
\end{tabular}

where W: Weak, M: Medium, S: Strong, VS: Very Strong

Table 3: Third Expert.

As mentioned above, each expert estimates each weight $\mathrm{Wij}$ between nodes $i$ and $j$, according to his/her experience. In order to be sure about experts' reliability, an algorithm is used to calculate both the weights of each interconnection and the credibility of experts. Each expert constructs his/her own weight matrix. Each weight Wij is collected and then they are compared according to the algorithm that follows. First of all, if the number of the weights with the same sign is less than $\mathrm{pi}^{\star} \mathrm{N}$, where $\mathrm{N}$ is the number of experts $(\mathrm{N}=3)$, then it is not clear if there is positive or negative causality between the nodes and the experts should redefine their weights. Otherwise, the process continues and the proposed weights are used to decide the weight eventually. Every expert who defines a weight that abstains from the average weight that the rest of experts have proposed will be penalized, and his reliability will be reduced. Moreover, his specific weight will not be taken into consideration. The same procedure is followed for each one element in the matrix separately. The use of this algorithm gives 
credence to our method. The experts should be sure for their decisions in order to retain their level of confidence high.

The above variables will be converted into numerical values with a defuzzification method. The Center of Area (COA) defuzzification method is one of the most commonly used defuzzification techniques. In this method, the fuzzy logic controller first calculates the area under the scaled membership functions and within the range of the output variable. The fuzzy logic controller then uses the following equation to calculate the geometric center of this area.

$$
\mathrm{y}_{\mathrm{coA}=}=\frac{\int_{\mathrm{s}} \mathrm{y}_{\mathrm{t}} \cdot \mu\left(\mathrm{y}_{\mathrm{t}}\right)}{\int_{\mathrm{s}} \mu\left(\mathrm{y}_{\mathrm{t}}\right)}
$$

where $S$ is the support set of the membership function of the output $\mu(y)$.

After COA defuzzification method the final weight matrix is illustrated in Figure 3.

It is considered that $\mathrm{k} 1=\mathrm{k} 2=1$ and $\lambda=1$.

The initial Fuzzy Cognitive Map with the first values of concepts is represented in Figure 4.

In the $1^{\text {st }}$ Case, the expert decided as initial values of the inputs the following: C1, C2, C3, C5, C6, C7: very strong, C4, C8, C9: strong

We considered initial values for the concepts after COA defuzzyfication method:

$\mathrm{W}=$
$\left[\begin{array}{cccccccccc}0 & 0.675 & 0 & -0.083 & 0 & 0.875 & 0.6875 & -0.167 & 0.25 & -0.875 \\ 0.875 & 0 & 0.25 & 0.33 & 0 & 0.8125 & 0.8125 & 0.675 & 0.5 & 0.425 \\ -0.25 & 0.4167 & 0 & 0 & -0.25 & 0 & 0 & 0 & -0.25 & -0.4167 \\ 0 & 0.25 & 0 & 0 & 0 & 0 & 0 & 0 & -0.167 & 0 \\ -0.167 & 0.167 & 0 & 0 & 0 & 0 & 0 & 0 & -0.25 & 0 \\ 0 & 0.25 & 0 & 0 & 0.083 & 0 & 0.33 & 0.25 & -0.4167 & 0 \\ 0 & 0.25 & 0 & 0 & 0 & 0.33 & 0 & 0.25 & 0.33 & 0 \\ 0 & 0.25 & 0 & 0 & 0 & 0.25 & 0.25 & 0 & -0.25 & 0.083 \\ 0 & 0 & 0 & 0 & 0 & 0 & 0.25 & -0.33 & 0 & -0.25 \\ 0 & 0 & 0 & 0 & 0 & 0 & 0 & 0 & 0 & 0\end{array}\right]$

Figure 3: The Final Weight Matrix.

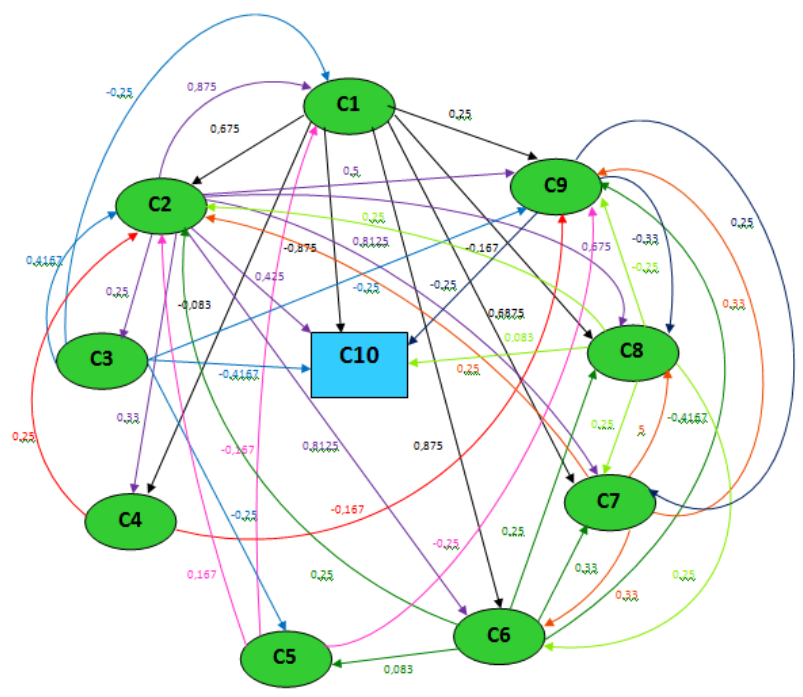

Figure 4: Fuzzy Cognitive Map.

\section{$\mathrm{A}(0)=\left[\begin{array}{llllllllll}1 & 1 & 1 & 0.75 & 1 & 1 & 1 & 0.75 & 0.75\end{array}\right]$}

The iterative procedure is being terminated when the values of concepts $\mathrm{C}_{i}$ have no difference between the latest two iterations. Considering $\lambda=1$ for the unipolar sigmoid function and after $\mathrm{N}=9$ iteration steps the system reaches an equilibrium point, where the values do not change any more from their previous ones (Figure 5).

We observe that the calculated value of the decision concept is $\mathrm{C}_{10}=0.951$, which corresponds to the $95.1 \%$ of the output. Consequently the lettuce is safe for consumption.

In the $2^{\text {nd }}$ Case, the second expert decided as initial values of the inputs the following: C1, C2, C3, C5, C6, C7: strong, C4, C8: medium, C9:weak

The representation of the concepts till their convergence illustrated in Figure 6.

The value of the decision concept is $\mathrm{C}_{10}=0,818$ which corresponds to the $81.8 \%$ of the output. It needed 10 iteration steps in order to reach to an equilibrium point. We conclude that the lettuce is also safe in this case.

In the $3^{\text {rd }}$ Case, the third expert decided as initial values of the inputs the following: C1, C3, C4: medium, C5, C6, C7: strong, C2, C8: weak, C9: zero

The output is $\mathrm{C}_{10}=0.43$, which corresponds to the $43 \%$ of the output (Figure 7). This means that we could not guarantee for the lettuce's health.

Computer-aided engineering (CAE) tools, where physical reality is replaced by its equivalent computer model, and which allows implementation of "what if" scenarios more quickly, can go a long way to increasing the efficiency and competitiveness of food product, process and equipment design. However, CAE tools that are customized to food processing and integrate several disciplines (e.g. engineering, food science, food technology, etc.) need to be appropriately developed. CAE tools can improve safety and quality, reduce costs and decrease "time to market".

Perrot et al., used the fuzzy symbolic approach for an application to a support system at a symbolic level to help the operators to evaluate the degree of cheese ripening during manufacturing on the basis of sensory measurements achieved on-line by the operators.

In the present study, nine concepts were selected as the most important ones concerning the lettuce production. Experts can quantify the risks associated with the practices of lettuce production from 'farm-to-fork'. The present model should be able to accurately describe the process by which contamination occurs and the impact to the endpoint of interest: human health.

Currently, uncertainty and ignorance about the hygienic effects of the individual operations during production, processing, and handling limit the applicability of a Decision Support System to specify HACCP criteria in a quantitative manner. The usefulness of the DSS is expected to be more significant with continuous improvement from collaboration of experts with different scientific background. Increased efficiency, productivity, and competitiveness are among the benefits of the use of the mathematical model. Moreover, it can offer cost effectiveness and high reliability. This could give to a vegetable business a comparative advantage over other competitors [41]. One of the biggest challenges for DSS is the ex-ante availability of real, relevant and representative data to base the decisions on complex problems that can arise during 


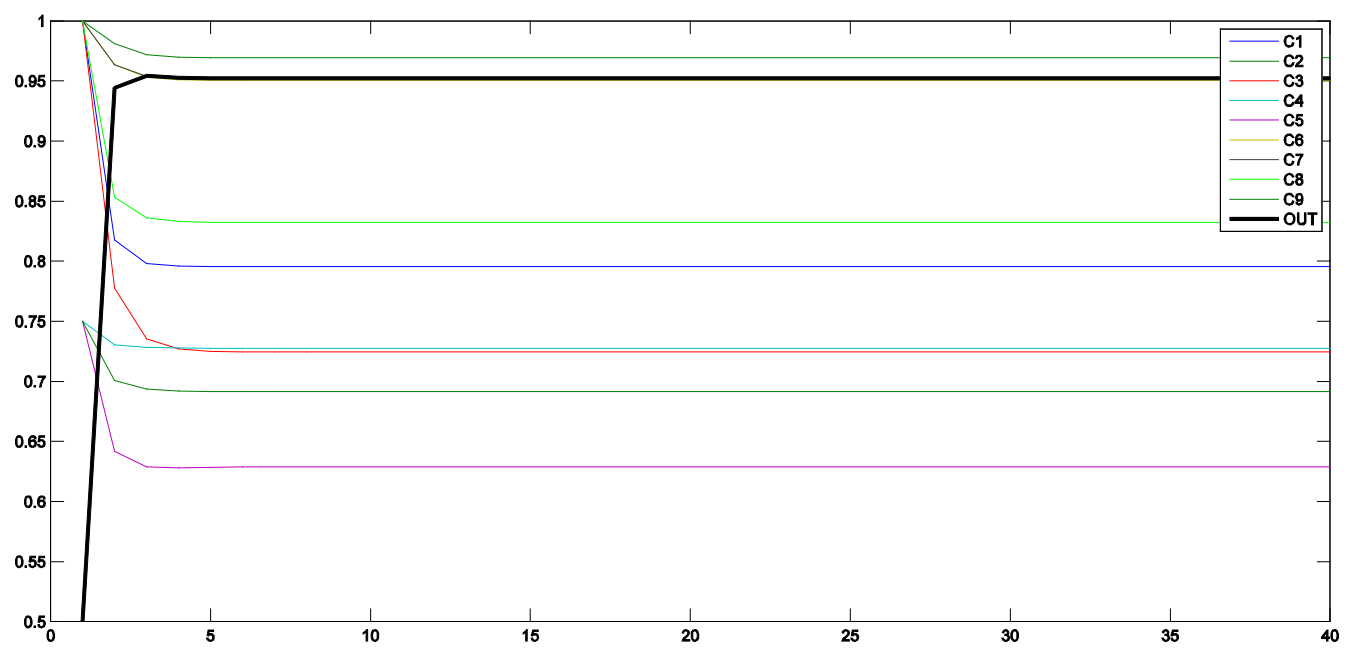

Figure 5: Subsequent values of concepts till convergence of $1^{\text {st }}$ case.

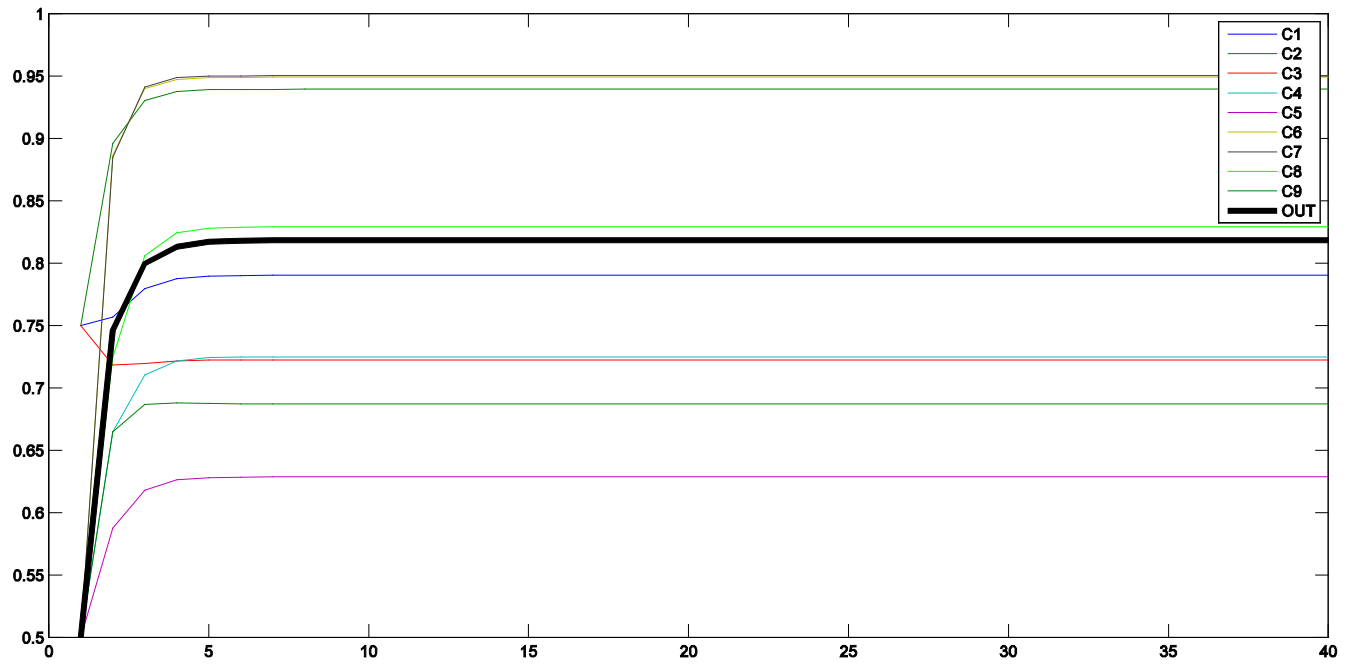

Figure 6: Subsequent values of concepts till convergence of $2^{\text {nd }}$ case.

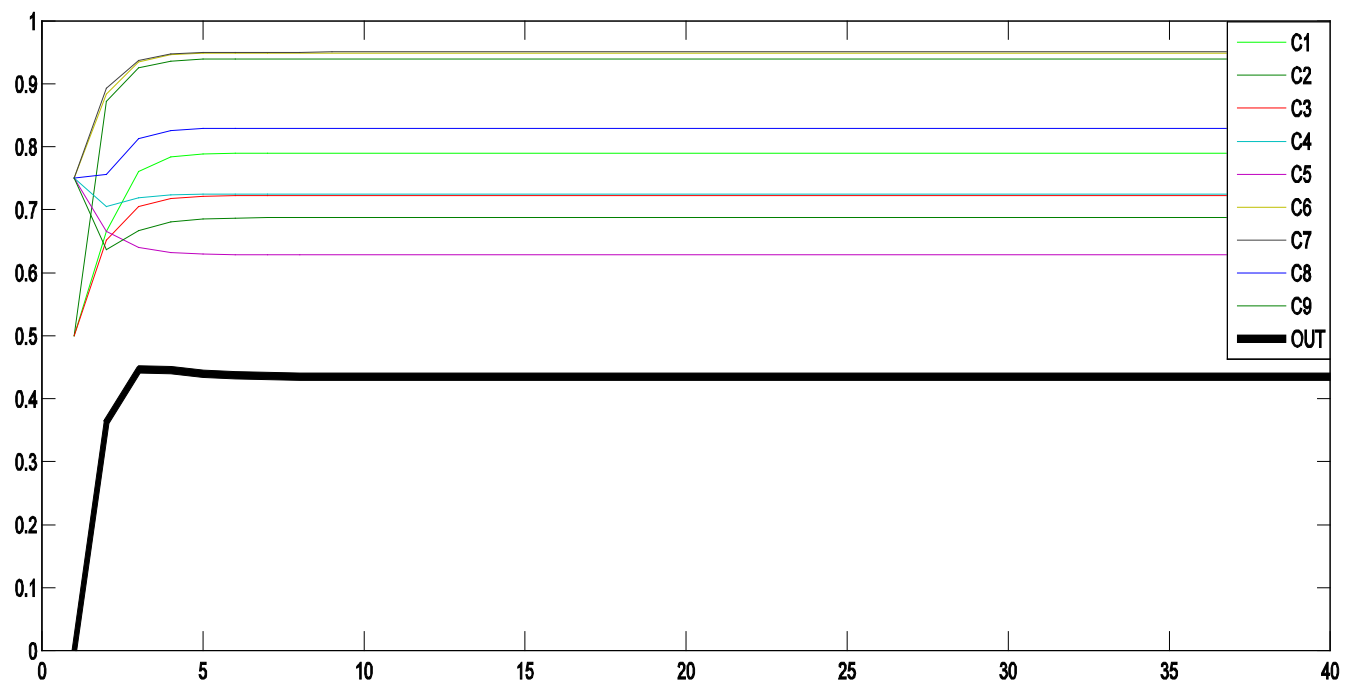

Figure 7: Subsequent values of concepts till convergence of $3^{\text {rd }}$ case. 
the food production. Thus DSS can be a valuable and easy tool that could be used on a daily basis not only from the industry itself but also from food authorities that can easily control the quality standards that must be met by foods provided for consumption in order to protect public health and to prevent consumers from fraudulent practises. It is suggested that all companies involved in the lettuce/leafy supply chains consider the recommendations contained within HACCP guidelines to ensure the safe production and handling of lettuce/ leafy greens products from field to fork. However, the use of software tools like Food Science Decision Support Systems (DSS) using theories of Fuzzy Cognitive Maps, which have not been yet widely used in Food Science, can be further explored and problems that can arise during the food production chain can be studied in order to indicate the importance of some critical control points during the food production in real time.

Microbiological and molecular analyses can support quality management of food product chains. However, the results of these analyses are time-consuming (microbiological analyses) and costconsuming (molecular assays). Moreover, the results depend on the accuracy and calibration of the equipments. The proposed model provides the quality and product managers of a vegetable company with a total new approach which is clear, simple, user friendly, realtime, easily accessible, fast, reliable, and of low-cost. In addition, the aforementioned software tool can support the Food Authorities to have on their desk a first evaluation of the products that they are going to inspect. The present model may be extended to other food commodities and the research team is currently working towards its commercialization.

\section{Highlights}

- Decision Support Systems (DSS) can make decisions in any complex system in the field of Food Science.

- Fuzzy Cognitive Maps (FCMs) are a combination of methods of fuzzy logic and neural networks.

Benefits of DSS in food industries are: efficiency, productivity, competitiveness, cost effectiveness and high reliability.

\section{References}

1. Gilbert LC (2000) The functional food trend: what's next and what American think about eggs. J Am Coll Nutr 19: 507-512.

2. IFIC (2000) International food information council functional foods attitudinal research.

3. Cox DN, Anderson AS, McKellar S, Reynolds J, Lean MEJ, et al. (1996) Vegetables and fruit: barriers and opportunities for greater consumption. Nutrition and Food Science 96: 44-47.

4. Leather S (1995) Fruit and vegetables: consumption patterns and health consequences. British Food Journal 97: 10-17.

5. Ragaert P, Verbekeb W, Devliegherea F, Debeverea J (2004) Consumer perception and choice of minimally processed vegetables and packaged fruits. Food Quality and Preference 15: 259-270.

6. Jacxsens L, Luning PA, van der Vorst JGAJ, Devlieghere F, Leemans R, et al. (2010) Simulation modelling and risk assessment as tools to identify the impact of climate change on microbiological food safety-The case study of fresh produce supply chain. Food Research International 43: 1925-1935.

7. Abadias M, Alegre I, Oliveira M, Altisent R, Viñas I (2012) Growth potential of Escherichia coli $\mathrm{O} 157: \mathrm{H} 7$ on fresh-cut fruits (melon and pineapple) and vegetables (carrot and escarole) stored under different conditions. Food Control 27: 37-44.

8. Olaimat AN, Holley RA (2012) Factors influencing the microbial safety of fresh produce: A review. Food Microbiol 32: 1-19.

9. FDA (2006) Commodity Specific Food Safety Guidelines for the Lettuce and
Leafy Greens Supply Chain.

10. Rodríguez-Caturla MY, Valero A, García-Gimeno RM, Zurera G (2012) Development of a risk-based methodology for estimating survival and growth of enteropathogenic Escherichia coli on iceberg-lettuce exposed at short-term storage in foodservice centers. Journal of Microbiological Methods 90: 273279

11. Zhou B, Feng H, Luo YG (2009) Ultrasound enhanced sanitizer efficacy in reduction of Escherichia coli $\mathrm{O} 157 \mathrm{H} 7$ population on spinach leaves. Journal of Food Science 74: 308-313.

12. Gardner TJ, Fitzgerald C, Xavier C, Klein R, Pruckler J, et al. (2011) Outbreak of Campylobacteriosis associated with consumption of raw peas. Clinical Infectious Diseases 53: 26-32.

13. Warning A, Datta A (2013) Interdisciplinary engineering approaches to study how pathogenic bacteria interact with fresh produce, Review. Journal of Food Engineering 114: 426-448.

14. Wijtzes T, van't Riet K, Huis in't Veld JHJ, Zwietering MH (1998) A decision support system for the prediction of microbial food safety and food quality. Int $J$ Food Microbiol. 42: 79-90.

15. Baranyi J, Jones A, Walker C, Kaloti A, Robinson TP, et al. (1996) A combined model for growth and subsequent thermal inactivation of Brochothrix thermosphacta. Appl Environ Microb 62: 1029-1035.

16. Van Impe JF, NicolaY BM, Martens T, De Baerdemaeker J, Vandewalle J (1992) Dynamic mathematical model to predict microbial growth and inactivation during food processing. Appl Environ Microbiol 58: 2901-2909.

17. Geeraerd AH, Herremans CH, Cenens C, Van Impe JF (1998) Application of artificial neural networks as a non-linear modular modelling technique to describe bacterial growth in chilled food products. International Journal of Food Microbiology 44: 49-68.

18. Perrot N, Agioux L, loannou I, Mauris G, Corrieu G, et al. (2004) Decision support system design using the operator skill to control cheese ripeningapplication of the fuzzy symbolic approach. Journal of Food Engineering 64: 321-333.

19. Halder A, Dhall A, Datta A, Glenn Black D, Davidson PM, et al. (2011) A userfriendly general-purpose predictive software package for food safety. Journal of Food Engineering 104: 173-185.

20. Groumpos PP (2010) Fuzzy Cognitive Maps: Basic Theories and their Application to Complex Systems 247: 1-22.

21. Groumpos PP, Stylios CD (2000) Modeling supervisory control systems using fuzzy cognitive maps. Chaos Solitons and Fractals 11: 329-336.

22. Huang Y, Lanb Y, Thomsona S, Fangc A, Hoffmannb W, et al. (2010) Development of soft computing and applications in agricultural and biological engineering. Computers and Electronics in Agriculture 71: 107-127.

23. CAC (2003) Recommended international code of practice, general principles of food hygiene. CAC/RCP 1-1969, Rev. 4-2003.

24. Garayoa R, Vitas Al, Díez-Leturia M, García-Jalón I (2011) Food safety and the contract catering companies: Food handlers, facilities and HACCP evaluation. Food Control 22: 2006-2012.

25. Himathongkham S, Bahari S, Riemann H, Cliver D (1999) Survival of Escherichia coli O157:H7 and Salmonella typhimurium in cow manure and cow manure slurry. FEMS Microbiol Lett 178: 251-257.

26. Melotto M, Underwood W, Koczan J, Nomura K, He SY (2006) Plant stomata function in innate immunity against bacterial invasion. Cell 126: 969-980.

27. Ge C, Lee C, Nangle Ed, Li J, Gardner D, et al. (2013) Impact of Phytopathogen Infection and Extreme Weather Stress on Internalization of Salmonella Typhimurium in Lettuce. International Journal of Food Microbiology.

28. Hasegawa PM, Bressan RA, Zhu JK, Bohnert HJ (2000) Plant cellular and molecular response to high salinity. Annu Rev Plant Mol Biol 51: 463-499.

29. Zhu JK (2001) Plant salt tolerance, Trends Plant Sci 6: 66-71.

30. Warriner K, Huber A, Namvar A, Fan W, Dunfield K (2009) Recent advances in the microbial safety of fresh fruits and vegetables. Adv Food Nutr Res 57 155-208.

31. Barrera M, Blenkinsop R, Warriner K (2012) The effect of different processing parameters on the efficacy of commercial post-harvest washing of minimally 
Citation: Birmpa A, Vantarakis A, Anninou A, Bellou M, Kokkinos P, et al. (2015) A User-Friendly Theoretical Mathematical Model for the Prediction of Food Safety in a Food Production Chain. J Food Process Technol 6: 421. doi:10.4172/2157-7110.1000421

processed spinach and shredded lettuce. Food Control 25: 745-751

32. Gil MI, Selma MV, Lopez-Galvez F, Allende A (2009) Fresh-cut product sanitation and wash water disinfection: problems and solutions. International Journal of Food Microbiology 134: 37-45.

33. Nou X, Luo Y, Hollar L, Yang Y, Feng H, et al. (2011) Chlorine stabilizer T-128 enhances efficacy of chlorine against cross-contamination by E. coli O157:H7 and Salmonella in fresh-cut lettuce processing. Journal of Food Science 76: 218-224.

34. Brown RS, Rizzo ED (2001) Methods for washing cores of cored lettuce heads. United States Patent.

35. FAO/WHO (2008) Microbiological hazards in fresh leafy vegetables and herbs. Expert Panel Report. Microbiological Risk Assessment Series, WHO Press.

36. Takeuchi K, Matute CM, Hassan AN, Frank JF (2000) Comparison of the attachment of Escherichia coli 0157:H7, Listeria monocytogenes, Salmonella typhimurium, and Pseudomonas fluorescens to lettuce leaves. Journal of Food Protection 63: 1433-1437.
37. Yang $Y$, Luo $Y$, Millner $P$, Turner $E$, Feng $H$ (2012) Assessment of Escherichia coli $0157: \mathrm{H} 7$ transference from soil to iceberg lettuce via a contaminated field coring harvesting knife. International Journal of Food Microbiology 153: 345-350.

38. Ding T, Iwahori J, Kasuga F, Wang J, Forghani F, et al. (2013) Risk assessment for Listeria monocytogenes on lettuce from farm to table in Korea. Food Control 30: 190-199.

39. Hoelzer K, Pouillot R, Gallagher D, Silverman MB, Kause J, et al. (2012) Estimation of Listeria monocytogenes transfer coefficients and efficacy of bacterial removal through cleaning and sanitation. International Journal of Food Microbiology 157: 267-277.

40. Wang J, Membré JM, Ha SD, Bahk GJ, Chung MS, et al. (2012) Modelling the combined effect of temperature and relative humidity on Escherichia coli 0157:H7 on lettuce. Food Science and Biotechnology 21: 859-865.

41. Nolan J (1997) A conceptual model for an intelligent fuzzy decision support system. Heuristics 10: 31-43. 